\title{
Improving water use efficiency in southern Alberta irrigated agriculture: choice of criterion
}

\author{
K. K. Klein ${ }^{1}$, S. N. Kulshreshtha ${ }^{2}$, M. K. Ali ${ }^{1} \&$ R. Bewer ${ }^{1}$ \\ ${ }^{I}$ Department of Economics, University of Lethbridge, Canada \\ ${ }^{2}$ Department of Bioresource PBE, University of Saskatchewan, Canada
}

\begin{abstract}
Irrigation accounts for the largest consumption of water in many areas of the world, including Alberta. As water supplies dwindle under the threat of climate change, several environmental lobby groups have argued that less water should be available for irrigation with the hope that more water would then be available for environmental objectives. The agricultural industry may be able to counteract these criticisms if its water use efficiency could be increased and substantiated. This requires selection of an appropriate criterion to use for measuring improvement in water use efficiency (WUE). In this study, two aspects of WUE are examined: Technical and Economic. Estimation is based on data for two river sub-basins where irrigation is practised in Alberta, using data over a five-year period, 2004-2008. The Oldman river sub-basin covers a larger area, and the amount of water diverted reflects it. Water use technical efficiency for this sub-basin was also higher than that for the Bow river sub-basin. Similar results were obtained for water use economic efficiency. On average, in the Oldman river sub-basin, one dam ${ }^{3}$ (1000 cubic meters) of irrigation water generates 4.4 tonnes of production, as against only 2.7 tonnes for the Bow river sub-basin. In terms of economic efficiency, water applied contributes on average, $\$ 171$ per $\mathrm{dam}^{3}$ for the Oldman versus only $\$ 115$ for the Bow river sub-basin. Final assessment of these measures suggests that the physical efficiency measures suffer from the limitation of ignoring the human aspect of efficiency improvement. Thus, improving the technical efficiency may not necessarily lead to improvement in human well-being, which is one of the major objectives of
\end{abstract}


irrigation development. Economic measures are, therefore, expected to provide a better measure of change in the human welfare and are recommended for future use, although even these can be improved further.

Keywords: water use efficiency, irrigation, Alberta, technical efficiency, economic efficiency.

\section{Background}

\subsection{Need for irrigation in Alberta}

To a great extent climate factors play a major role in determining the type and extent of agricultural production in Canada. According to Shady [1], Southern Alberta is one of the regions in Canada where average water deficits are in excess of $200 \mathrm{~mm}$, partly as a result of the dry and sunny climate in general. Dale-Burnett [2] described the region as the 'Palliser Triangle', (named after John Palliser, a British explorer), a region that was declared unfit for agriculture. The development of irrigation has made this region one of the most productive agricultural areas in Canada. Therefore, irrigation is a virtual necessity in the southern part of the province.

The application of supplementary water, also known as irrigation, started in the province in the late $1880 \mathrm{~s}$. By the early 1900s, major irrigation projects were operating. In 1914, the province of Alberta passed the Irrigation Districts Act. This provided the basis for irrigation water use under 13 irrigation districts. However, some private irrigation also exists in the province, although these areas are spread throughout the province. At the present time, 625,000 hectares are irrigated in the province. Irrigation in the province is a major user of water. Beaulieu et al. [3] estimated that in 2001, irrigation in Alberta used 2.9 billion $\mathrm{m}^{3}$ of water, some $66 \%$ of total irrigation water in Canada. Thus, on average every hectare of irrigated land receives $5,524 \mathrm{~m}^{3}$ of water annually.

The source of water for virtually all irrigation in Alberta is surface run-off. The majority of this water comes from snowmelt on the eastern slopes of the Rocky Mountains. Groundwater, although available, is not used for irrigation in any appreciable quantities.

\subsection{Nature of technology used and crop mix}

Irrigation in southern Alberta is effected using a system of more than 8,000 kilometres of conveyance works and more than 50 water storage reservoirs. Across the irrigated land in the province, irrigation producers are able to grow a great diversity of crops, many of which can be successfully produced only under irrigation, partly because naturally-available moisture for crop growth is generally less than half that required and is very erratic in its distribution. With more than 40 different types of crops being grown, irrigation water users have the flexibility needed to sustain viable farm enterprises, even during times with market swings in commodity prices. 


\subsection{Irrigation and diversification}

Irrigation in Alberta is unquestionably a significant part of the agricultural landscape, occurring on less than $6 \%$ of the cultivated land base in the province, but contributing more than $19 \%$ of the gross primary agricultural production. In addition, irrigation provides avenues for diversification on farms as well of the regional economy. Irrigation is also an effective drought mitigation measure.

\section{Need for the study}

Water requirements for irrigation vary from year to year depending on weather conditions. In general, weather is the greatest factor driving demand for irrigation water, although the type of crops being grown also influences its demand. Demand for irrigation water is highest when it is a relatively hot and dry year, but those are also typically the years when the available supply of irrigation water tends to be less. In wetter years, there is generally more water available to divert but crops may not need as much irrigation water. This balance between supply and demand can be partially addressed by adoption of water conservation measures.

With irrigation, the majority of water that is applied to crops is taken up by the plants for growth, or evaporated. There is also some amount of water that is never used for irrigation itself, but is needed to maintain the minimum depth of water in canals and reservoirs in order to transport irrigation water through the system; therefore some of this water ends up as return flow back into other creeks and rivers.

As water supplies dwindle under the threat of climate change, several environmental lobby groups have argued that less water should be made available for irrigation (with the hope that more water would then be available for environmental objectives). The increasing criticism of water used for irrigating crops could threaten its long-term sustainability. The agricultural industry may be able to counteract criticisms of environmental lobby groups by improving irrigation water use efficiency. Irrigation water users and their organizations (including public bodies) are constantly evaluating their infrastructure and irrigation practices to minimize water losses (through seepage and evaporation) and maximize the area that can be irrigated. Improving water use efficiencies mean that less water is needed to produce the same amount of crop, or, that more area can be irrigated with the same amount of water. As available water is fully allocated, the only way to increase irrigation is through improving its efficiency of use.

One of the major attempts to bring the need for water conservation into public attention and focus was release of a Water for Life strategy that was released by the government of Alberta in 2003 [4]. The strategy includes measures to improve ability to capture and store water during high flow periods and to improve water use practices through conservation, efficiency, and productivity efforts, thereby tackling the challenge of unpredictable water supplies. Water conservation, efficiency, and productivity are fundamental in this water strategy. 


\section{Measurement of water use efficiency}

Conserving water and improving efficiency of water use are somewhat related concepts. Improving water use efficiency is one of the measures that can lead to water conservation and thus, making water available for alternative users. In light of almost fully allocated water availability, improving water use efficiency is most welcome by water managers. A question arises as to what is an appropriate measure of water use efficiency.

Several researchers have used different definitions and concepts for measuring irrigation water use efficiency. Some define it as a dimensionless measure in terms of a ratio or percentage while others define it in terms of outputs measured in physical or monetary units per unit of water used. Variations and refinements in the definitions of the numerator and denominator also are common in the literature. For example, Seckler et al. [5] defined irrigation water use efficiency as the ratio of the net evapotranspiration to the amount of water withdrawn or diverted, where net evapotranspiration is the crop evapotranspiration requirements minus effective precipitation. Dhehibi et al. [6] presented a method of measuring efficiency of irrigation water use based on a non-radial notion of input-specific technical efficiency derived from a stochastic production frontier. This measure referred to the irrigation efficiency as the ratio of minimum feasible water use to the observed water use considering the output and inputs used with the production technology. Solomon and Burt [7] defined 'irrigation sagacity' as the ratio of irrigation water used 'beneficially or reasonably' to the irrigation water applied adjusted for the change in the storage of irrigation water. This definition is somewhat different from the authors' earlier definition of 'irrigation efficiency.' Obviously, these criteria require increasingly sophisticated and hard to obtain data. The terms 'beneficially or reasonably' in the definition of [7] are more likely to invite controversy rather than providing a more accurate measure of irrigation efficiency.

In contrast, the OECD [8] and Tollefson et al. [9] have defined water use efficiency in terms of physical and economic outputs per unit of water use, which could more easily be calculated with data commonly found in published sources and government documents. The first indicator of water use efficiency is called water use technical efficiency (WUTE) and defined as the mass of irrigated output divided by the volume of irrigation water utilized (e.g., tonnes $/ \mathrm{dam}^{3}$ ) while the second indicator is called water use economic efficiency (WUEE) and defined as the dollar value of irrigated output divided by the volume of irrigation water utilized (e.g., $\$ / \mathrm{dam}^{3}$ ). Even though the concept of efficiency is generally perceived in terms of a percentage or a unit free measure, the WUTE and WUEE, nonetheless, provide common sense yardsticks of the opportunity cost of a unit of irrigation water in physical and economic terms. Because of their computational ease, these two criteria of water use efficiency are evaluated in this paper in the following sections. 


\subsection{Water use technical efficiency}

As mentioned earlier, the OECD [8] report defines water use technical efficiency (WUTE) as mass of agricultural production (in tonnes) per unit of water used. The WUTE is typically conceptualized in terms of level of irrigation water use and all the productivity is credited to it. The crop water use needs to be adjusted for return flow and precipitation amounts.

\subsection{Water use economic efficiency}

Technical water use efficiency indicator assumes that all crops grown under irrigation have the same impact on the well-being of the irrigator. However, such an assumption is not supported by real situations. Some irrigated crops are higher value crops while other crops are very low in value. Further complications arise from the fact that some crops under irrigated production systems are intermediate crops and therefore, not typically sold in a market place. A case in question is forages, which are primarily used for beef cattle enterprises. Water use economic efficiency (WUEE) removes this limitation of the technical water use indicator. It is defined as the ratio of total monetary value of agricultural production per unit of irrigation water utilized. Estimation of WUEE also is fairly data intensive since it requires knowledge of market prices, and disposition of various crops, in addition to cost of production. Further complications arise when some crops are marketed directly while others are for on-farm use and, therefore, marketed indirectly.

A major limitation of this indicator is that it is highly susceptible to changes in several factors, including choice of crops planted, agronomic/cultural practices employed, and crop prices. For example, adding more fertilizer to a crop usually increases its yield, and unless market price changes as a result, also increases the gross revenue obtained. This would result in a higher estimated value of WUEE but the change is contributed by factors other than improved water use technical efficiency.

\section{Methods}

In this study, the above two water use efficiency indicators (WUTE and WUEE) were estimated for irrigated agriculture in two river sub-basins - Oldman river sub-basin and the Bow river sub-basin, in Alberta following the definitions of OECD [8]. These sub-basins were selected as these have the largest area of irrigation in Alberta. The Oldman river sub-basin is about $75 \%$ larger than the Bow river sub-basin in terms of the volume of water diverted. The location of these two sub-basins is shown in Figure 1.

The total production (in metric tonnes) that was grown in each of these river sub-basins was calculated for each of the years 2004, 2005, 2006, 2007, and 2008 (see Yan et al. [10] for details). The total mass was calculated by multiplying the yield in metric tonnes by the number of hectares for each crop in each year. The yield was held constant at the 2000-2004 average to ensure that 


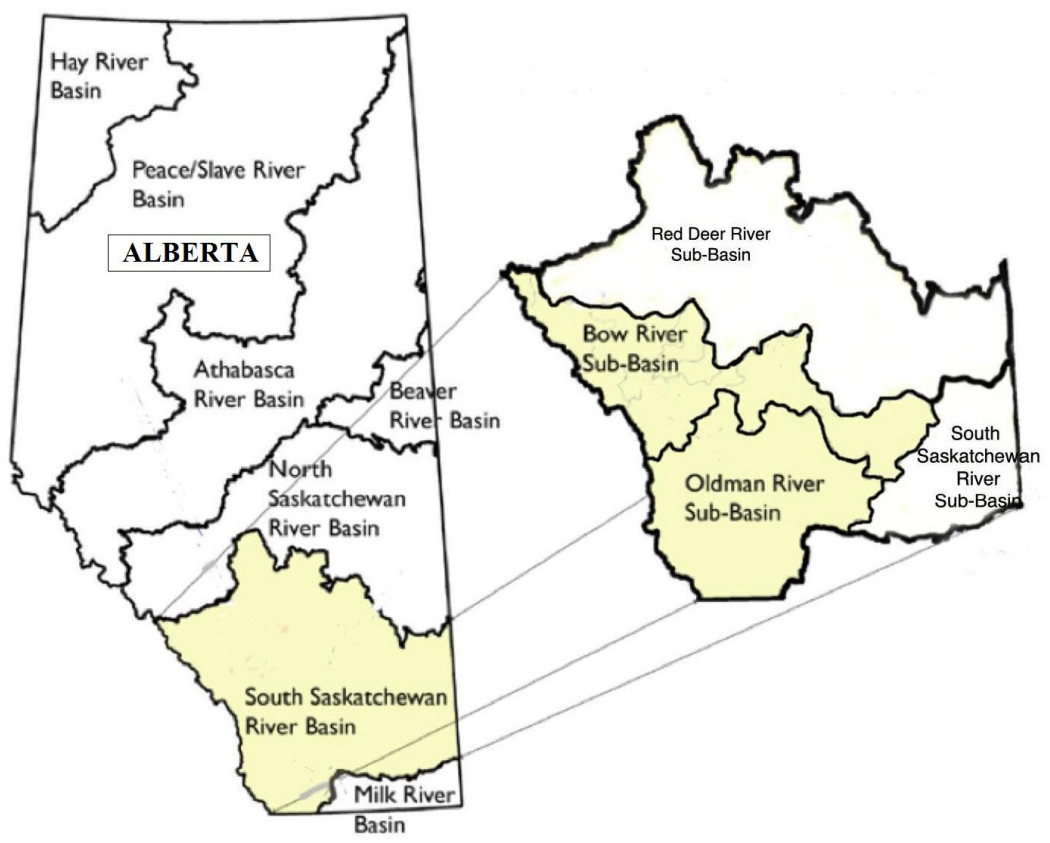

Figure 1: Location of the Bow river sub-basin and Oldman river sub-basin in the South Saskatchewan River Basin (SSRB), Alberta.

the annual changes in yields would not affect the calculation of water use efficiencies. Since small changes occur annually in areas planted to each crop under irrigation (in response to output and input prices, rotational considerations and other factors), the total mass produced in each of the river sub-basins changes year-by-year.

Two measures of the value of production were calculated for each of the river sub-basins: gross revenues and net revenues (gross revenues less variable costs of production). Annual realized farm level prices were multiplied by average yields and by hectares of each crop to arrive at the gross revenues of crops produced. All variable costs of production were subtracted from the gross revenues to arrive at the net revenues.

The denominator for each of the efficiency measures is the gross water diverted to the irrigation districts in these two sub-basins in each year. For these calculations, we used the somewhat broader measurement of total water diverted from each sub-basin in dam $^{3}$ (AAFRD [11]). In addition to the water used for irrigation, this includes water used for industries, municipal, domestic, and environmental purposes. Due to the unavailability of data, return flows are also not subtracted from the gross diversion volumes. Thus, the data used in the denominator are slightly larger than the actual volume of water used for irrigation. However, the predominant use of water diversions in these two sub- 
basins is for irrigation and it is assumed that the water used for other purposes is constant from one year to the next.

All data for this analysis came from AAFRD [11-13], which reported areas planted to each crop, yields, prices, costs of production, and water diversion volumes during the time period studied.

\section{Results}

Table 1 presents data on the gross diversion of water in the Oldman and Bow river sub-basins of the SSRB for the period 2004-2008 while Table 2 presents calculations for the two measures of water use efficiency - WUTE and WUEE. The WUTE averaged 4.411 over the five-year period for the Oldman river subbasin and 2.722 for the Bow river sub-basin. This means that a higher tonnage of crop is produced per $\mathrm{dam}^{3}\left(1000 \mathrm{~m}^{3}\right)$ of water used in the Oldman river subbasin. Water use technical efficiency also exhibited variability over time in each of the river sub-basins, perhaps due to a combination of factors that are external to the amount of irrigation water used. Examples of these external factors include planting of different crop mixes to take advantage of changing crop prices with different crops requiring different amounts of water, changes in the fertilizer mixture used to produce the crop resulting in changes in yield, differing soil composition between regions, and unexpected events such as weather, disease, and insects. Soil composition differences may also partially account for the difference in water use efficiency between the two sub-basins.

Table 1: $\quad$ Gross diversion of water 2004-2008 $\left(1000 \mathrm{~m}^{3}\right)$.

\begin{tabular}{|c|c|c|}
\hline Year & Bow river sub-basin & Oldman river sub-basin \\
\hline 2004 & 457,056 & 693,471 \\
\hline 2005 & 375,183 & 596,919 \\
\hline 2006 & 370,081 & 700,072 \\
\hline 2007 & 442,589 & 897,693 \\
\hline 2008 & 437,565 & 753,329 \\
\hline Average & 416,495 & 728,297 \\
Std. dev. & 40,715 & 110,217 \\
\hline
\end{tabular}

Two measures of water use economic efficiency were calculated for the two sub-basins for the period of 2004-2008: WUEE (gross) and WUEE (net). The WUEE (gross) is the measure suggested by the OECD [8] and uses the gross revenue from production as the numerator. The WUEE (gross) averaged \$289.58 per dam ${ }^{3}$ over the five-year period in the Bow river sub-basin and averaged $\$ 423.25$ per dam $^{3}$ in the Oldman river sub-basin (Table 3). The WUEE (net) averaged $\$ 114.56$ per dam ${ }^{3}$ in the Bow river sub-basin and $\$ 170.87$ per dam ${ }^{3}$ in the Oldman river sub-basin. The major advantage of the WUEE (net) calculation is that it accounts for changes in costs as well as revenues from crop production 
Table 2: Water use technical efficiency (WUTE) 2004-2008 (tonnes/ $\left.1000 \mathrm{~m}^{3}\right)$.

\begin{tabular}{|c|c|c|}
\hline Year & Bow river sub-basin & Oldman river sub-basin \\
\hline 2004 & 2.557 & 4.520 \\
\hline 2005 & 3.093 & 5.373 \\
\hline 2006 & 3.134 & 4.690 \\
\hline 2007 & 2.566 & 3.599 \\
\hline 2008 & 2.262 & 3.872 \\
\hline Average & 2.722 & 4.411 \\
Std. dev. & 0.378 & 0.701 \\
\hline
\end{tabular}

Table 3: Water use economic efficiency (WUEE) 2004-2008 (Can \$/ $\left.1000 \mathrm{~m}^{3}\right)$.

\begin{tabular}{|c|c|c|c|c|}
\hline & \multicolumn{2}{|c|}{ WUEE (gross) } & \multicolumn{2}{c|}{ WUEE (net) } \\
\hline Year & Bow & Oldman & Bow & Oldman \\
\hline 2004 & 233.65 & 405.57 & 79.20 & 125.41 \\
\hline 2005 & 307.64 & 468.12 & 128.98 & 207.42 \\
\hline 2006 & 288.74 & 406.38 & 109.03 & 176.72 \\
\hline 2007 & 267.75 & 345.34 & 101.88 & 135.75 \\
\hline 2008 & 350.12 & 490.83 & 153.71 & 209.07 \\
\hline $\begin{array}{c}\text { Average } \\
\text { Std. dev. }\end{array}$ & 289.58 & 423.25 & 114.56 & 170.87 \\
& 43.58 & 57.55 & 28.21 & 39.14 \\
\hline
\end{tabular}

and thus reflects more closely the profitability signals to which farmers respond. Since output prices vary year-by-year, there is quite a lot of variability in the measures of WUEE (gross). Of course, input prices also vary, as do the amounts of inputs committed. But there is less year-to-year variability in the WUEE (net) measure.

\section{Discussion}

In this study water use efficiency in the two largest irrigation sub-basins in Alberta was examined using both technical and economic criteria. Although each can be conceptualized in different forms, in this study WUTE was defined as the total tonnage of agricultural products produced in the river sub-basins per unit of water diverted (measured in cubic decametres or dam ${ }^{3}$ ). The economic efficiency 
took the technical efficiency one step further by weighting the physical quantities by their respective economic (social) values, still expressing it per unit of water. Two different measures of WUEE were developed: one calculated gross revenue per unit of water, the other calculated net revenue per unit of water.

Results suggest that WUTE does not vary as much from year to year as does either of the two WUEE measurements. The coefficient of variation for the WUTE is lower than that for either the gross or net WUEE.

For comparisons over a period of time, the WUTE indicator has some weaknesses, including:

- One, moisture to produce a crop comes from two sources: natural rainfall and supplementary irrigation water. In this measure, natural precipitation is ignored. Since some years have above normal rainfall, while others may be drought-like, the WUTE can produce misleading and even contradictory results. Producers generally adjust the level of supplementary irrigation water for various crops under different weather conditions.

- Two, the measure, in addition to not being comparable over time, also is not comparable over various regions on account of differences in crop mix, productivity of soils, weather patterns and other factors. Bulky crops, such as forages, generally are higher tonnage crops than are cereals or oilseed crops, therefore distorting the measure. Furthermore, the numerator in this measure does not take into account the total amount of biomass produced for all crops. For forages, the amount included is the total harvestable biomass, whereas only the weight of the seeds harvested is counted for grains and oilseeds.

- Three, this indicator uses the amount of water used in the denominator, which may also suffer from different definitions - water diverted, water applied by producers, water consumed, among others.

The first limitation of the WUTE can be removed by adopting an alternate measure of technical efficiency - incremental WUTE. In this measure, only incremental yield over the dryland production system would be included. This is based on the assumption that the natural precipitation will produce a yield equivalent to the dryland production system and the remaining increase in the yield under irrigation is due to supplementary irrigation. However, calculation of this measure requires data on dryland yields under equivalent conditions.

With respect to the denominator - amount of irrigation water used, refinements in its definition also could produce an improved measure of WUTE. For example, Tollefson et al. [9] has suggested two measures of this water: water diversion and water consumed. The latter is the difference between water diverted and water returned back to the source (perhaps at another location). The latter would yield a better measure of irrigation WUTE. Furthermore, water diversions also reflect water delivery efficiency to producers. Improvements in water delivery efficiencies (such as converting open canals to pipelines) could significantly improve both WUTE and WUEE. 
The economic efficiency measure is an improvement over technical efficiency since it provides a measurement that is closer to the overall objective of irrigation farmers - improve their profitability and thereby overall social wellbeing. However, refinements in this indicator also can be suggested, in addition to those noted above. These include defining the numerator as the extra revenue obtained above what would have occurred under a dryland system. This is a more complicated calculation and would require yield and costs data for dryland production of various crops and weighting the values to reflect an aggregate WUEE.

\section{References}

[1] Shady, A. M., Irrigation, drainage and flood control in Canada. Ottawa: Canadian International Development Agency, 1964.

[2] Dale-Burnett, L., Palliser Triangle. The encyclopedia of Saskatchewan. Canadian Plains Research Center, University of Regina, Regina, p. 678, 2002.

[3] Beaulieu, M. S., Fric, C., and Soulard, F., Estimation of water use in Canadian agriculture. Statistics Canada, Ottawa. 40 pp. 2007.

[4] Government of Alberta. Water for life action plan. Edmonton. 28 pp. 2006.

[5] Seckler, D., Molden, D., \& Sakthivadivel, R., The concept of efficiency in water-resources management and policy (chapter 3). Water Productivity in Agriculture: Limits and Opportunities for Improvement, ed. Kijne, W., Barker, R., \& Molden, D., International Water Management Institute, Colombo, Sri Lanka, pp. 37-51, 2003.

[6] Dhehibi, B., Lachaal, L., Elloumi, M., \& Messaoud, E.B., Measuring irrigation water efficiency with a stochastic production frontier: an application for Citrus producing farms in Tunisia. American Agricultural Economic Association Conference Proceedings, pp. 449-457, 2007.

[7] Solomon, K.H. \& Burt, C.M., Irrigation sagacity: a measure of prudent water use. Irrigation Science, 18, pp.135-140, 1999.

[8] OECD - Organization for Economic Cooperation and Development. Environmental indicators for agriculture - methods and results. Volume 3. Paris. 2001.

[9] Tollefson, L., Harrington, J., \& Hogg, T., Water quantity and use efficiency indicators for Canada. p. 3-11. Agricultural Water Quality and Water Use: Developing Indicators for Policy Analysis. Proceedings of an OECD Expert Meeting-Gyeongju, ed. Parris, K. \& Jung, P.K. The Republic of Korea, October 2003.

[10] Yan, W., Klein, K. K., \& Le Roy, D.G., Estimating the net benefits of irrigation water for cropping activities in irrigation districts in southern Alberta. SAREC Report 2010-1, Department of Economics, University of Lethbridge, 2010, 58 pages.

[11] Alberta Agriculture, Food and Rural Development (AAFRD). Alberta irrigation districts - Alberta irrigation information for the years 2004-2008. Irrigation Division, AAFRD, Lethbridge, Alberta. 2005-2009. 
[12] Alberta Agriculture, Food and Rural Development (AAFRD). AgriProfit\$ benchmarks for Alberta crop and forage producers. Edmonton. 2004-2007.

[13] Alberta Agriculture, Food and Rural Development (AAFRD). AgriProfit\$ cropping alternatives. Edmonton. 2008. 